\title{
Effects of triptolide on bone marrow-derived mesenchymal stem cells from patients with multiple myeloma
}

\author{
HAIYING WU ${ }^{1}$, YUANTING WU ${ }^{2}$, LI REN ${ }^{1}$, WO ZHAI ${ }^{1}$, YUXIA JIANG ${ }^{1}$, SHUPING GUO $^{1}$, \\ DIEHONG TAO ${ }^{1}$, CHUANYONG SU $^{1}$, ZHILU CHEN ${ }^{1}$ and HUIFANG JIANG ${ }^{1}$ \\ ${ }^{1}$ Department of Hematology, Tongde Hospital of Zhejiang Province, Hangzhou, Zhejiang 310012; \\ ${ }^{2}$ The Second Clinical Medical College, Zhejiang Chinese Medical University, Hangzhou, Zhejiang 310053, P.R. China
}

Received November 25, 2017; Accepted August 17, 2018

DOI: $10.3892 / \mathrm{etm} .2019 .7373$

\begin{abstract}
Triptolide (TPL), an extract of the Chinese herb Tripterygium wilfordii Hook F, is a potent anti-inflammatory agent that further possesses anticancer activity. Its antiproliferative effects are well established. Only few studies have focused on TPL as a potential treatment in multiple myeloma (MM). In the current study, bone marrow-derived mesenchymal stem cells (BMMSCs) from patients with MM were isolated and treated with TPL at varying concentrations. Thalidomide is currently used as a positive control drug in the treatment of MM. Cell Counting kit- 8 assays were performed to assess proliferation activity and flow cytometry with Annexin V-fluorescein/propidium iodide was used to detect cell apoptosis of TPL-treated BMMSCs. Reverse transcription-quantitative polymerase chain reaction assays were applied to measure interleukin (IL)-6, IL-1 $\beta$ and stem cell factor (SCF or Kit ligand) mRNA expression and western blot assays were performed to analyze transcription factor p65 (P65) expression in TPL-treated BMMSCs. ELISA was applied to measure vascular endothelial growth factor (VEGF) levels in the supernatant of the cultured and treated BMMSCs. TPL treatment significantly inhibited BMMSC proliferation compared with the untreated control $(\mathrm{P}<0.05)$. At $48 \mathrm{~h}$ following TPL treatment, a Cell Counting kit- 8 study was performed and the $\mathrm{IC}_{50}$ value was determined at $101.55 \pm 2.45 \mathrm{ng} / \mathrm{ml}$. Apoptotic rates were observed to increase with increasing concentrations of TPL $(\mathrm{P}<0.001)$, and IL-6, IL-1 $\beta$ and SCF mRNA expression was significantly decreased with increasing TPL $(\mathrm{P}<0.001)$.
\end{abstract}

Correspondence to: Dr Huifang Jiang, Department of Hematology, Tongde Hospital of Zhejiang Province, 234 Gu Cui Road, Hangzhou, Zhejiang 310012, P.R. China

E-mail: jhf501@139.com

Abbreviations: TPL, triptolide; BMMSC, bone marrow-derived mesenchymal stem cell; MM, multiple myeloma; VEGF, vascular endothelial growth factor

Key words: triptolide, multiple myeloma, bone marrow-derived mesenchymal stem cells, cytokines, nucleation factor- $\kappa \mathrm{B}$
P65 expression following TPL treatment was significantly decreased compared with the untreated control $(\mathrm{P}<0.05)$. VEGF levels were significantly reduced in the presence of increasing amounts of TPL $(\mathrm{P}<0.05)$. These findings suggest that TPL inhibited BMMSC growth and improved the bone marrow hematopoietic microenvironment by decreasing IL-6, IL-1 $\beta$ and SCF mRNA expression, subsequently inhibiting the proliferation of MM cells. Therefore, TPL may be used in the future to treat patients with MM.

\section{Introduction}

Multiple myeloma (MM) is a malignant plasma hematologic tumor and a potent radical treatment is currently not available (1). Thus, it is considered as an incurable tumor. The incidence rate is estimated to be 2-3/100,000, with a male to female ratio of 1.6:1 and a median age of 65 years. Novel drugs for the treatment of MM include second generation of proteasome inhibitors, such as carfilzomib, third generation of immunomodulators, such as pomalidomide and monoclonal antibodies, such as daratumumab. The Tripterygium wilfordii extract triptolide (TPL), a Traditional Chinese Medicine, possesses significant anti-inflammatory, antitumor and immunoregulatory effects, and regulates fertility $(2,3)$. According to previous studies (4-8), TPL has been reported to decrease the activity of nucleation factor (NF)- $\kappa \mathrm{B}$ in lymphocytes, endothelial cells and other cells, and further to decrease the levels of inflammatory mediators, including interleukin (IL)-6 and IL-1 $\beta$, which are released in the activation of NF- $\kappa$ B. In previous studies, TPL was observed to inhibit cyclin D1 expression through blocking the signal transducer and activator of transcription 3 signaling pathway and mRNA expression of the positive cell cycle regulatory genes, including c-myc and cyclin A, B, C and D, in various colon cancer cell lines $(9,10)$. Constitutive activation of the $\mathrm{NF}-\kappa \mathrm{B}$ pathway is mediated by mutations in certain tumors during progression, such as hepatocellular carcinoma (11). In addition to these oncogenic events, tumor cells are strongly dependent on the bone marrow (BM) microenvironment (12). Substantial advances have been made in understanding the biology of MM by studying the BM microenvironment $(13,14)$. The BM niche serves an important role in differentiation, migration, proliferation, survival and drug resistance of malignant plasma cells (15). It has further 
been reported that the BM is closely associated with MM, its cell growth, survival and drug resistance (16). These findings provide preclinical evidence for the potential application of BM-derived mesenchymal stem cells (MSCs) as antitumor treatment in MM. The cellular compartment is composed of hematopoietic and non-hematopoietic cells, including fibroblasts, BMMSCs, endothelial cells, osteoclasts and osteoblasts (17). The non-cellular compartment is composed of the extra cellular matrix (ECM) and the liquid milieu, containing cytokines (IL-6, IL-1 $\beta$ ), growth factors and chemokines (17). MM cells can form masses around the BM and adhere to ECM proteins and BM stromal cells (BMSCs) (18). This relocation allows the progression and metastasis of MM to further BM locations (15).

Due to the increasing prices of imported drugs, patients in China cannot afford treatment, including bortezomib and lenalidomide. For example bortezomib costs 6,116 renminbi (RMB)/dose; every patient requires 4-6 courses and each course consisted of 4 doses. The total cost of bortezomib is $>100,000 \mathrm{RMB}$. A total of 21 doses of lenalidomide cost 23,141 RMB for $25 \mathrm{mg}$ doses and 18,186 RMB for $10 \mathrm{mg}$. Patients on lenalidomide need to administer the drug for 1-2 years. TPL, a traditional Chinese medicine that can be administered orally and intravenously, is inexpensive. Hence, the current study aimed to elucidate the potential application and effectiveness of TPL in the treatment of MM and to provide an experimental basis for clinical applications.

\section{Materials and methods}

BMMSCs. BMMSCs were obtained from 10 patients with MM (age range, 40-80 years; mean age, 63 \pm 9.7 years; 4 females and 6 males) recruited at the Tongde Hospital of Zhejiang Province (Hangzhou, China) between October 2014 and September 2015. The study was approved by the Ethics Committee of Tongde Hospital of Zhejiang Province (Hangzhou, China) and patients provided written informed consent.

The following diagnostic criteria applied: i) Symptomatic MM: Presence of $\mathrm{M}$ protein in serum or urine; cloned plasma cell or plasma cell tumor in the BM; relevant organ or tissue damage, including anemia, hypercalcemia, renal damage and bone lesions. ii) Asymptomatic myeloma (smoldering myeloma); serum $\mathrm{M}$ protein reach myeloma level (>30 g/l); $\geq 10 \%$ clonal plasma cells in the BM; no associated organ or tissue damage or MM-associated symptoms.

Inclusion criteria were defined as follows: i) Meet diagnostic criteria of MM; ii) onset of disease without remission or relapse; iii) aged 18-80 years; iv) Eastern Cooperative Oncology Group score <2 (19). Exclusion criteria were as follows: i) Perinatal women or mentally ill patients; ii) history of underlying liver or kidney disease; iii) other hematological malignancies.

The majority of patients with MM had M protein levels $>30 \mathrm{~g} / \mathrm{l}, \mathrm{IgA}>25 \mathrm{~g} / \mathrm{l}$ and $24-\mathrm{h}$ urine light chains $>1 \mathrm{~g}$, some patients exhibted lower $M$ protein levels. A previous study reported that the the number of plasmacytoid plasma cells in the BM were $>10 \%$ in $95 \%$ of patients (20). Clinical manifestations of associated target organ damage, including anemia, osteolytic lesions, hypercalcemia, renal insufficiency, hyperviscosity syndrome, amyloidosis and recurrent infections, were further important diagnostic criteria in patients with MM.

Reagents and equipment. TLP and thalidomide were purchased from Sigma-Aldrich (purity, >98\%; Merck KGaA, Darmstadt, Germany). Low-glucose Dulbecco's modified Eagle's medium (DMEM) was purchased from Gibco (Thermo Fisher Scientific, Inc., Waltham, MA, USA). Fetal bovine serum (FBS) was purchased from Boehringer Ingelheim $\mathrm{GmbH}$ (Ingelheim, Germany) and the Cell Counting kit-8 (CCK-8) was from Dojindo Molecular Technologies, Inc. (Kumamoto, Japan). Dimethyl sulfoxide (DMSO) was from Sangon Biotech Co., Ltd. (Shanghai, China), the Annexin V-fluorescein isothiocyanate (FITC) and propidium iodide (PI) kit was supplied by Hangzhou MultiSciences (Lianke) Biotech Co., Ltd. (Hangzhou, China). Human BM mononuclear lymphocytes separating medium was obtained from Tianjin Haoyang Biological Products Technology Co., Ltd. (TBD2013LHU; Tianjin, China) and antibodies for CD34 phycoerythrin (PE; cat.no. A07776), CD45 PE (cat.no. IM3548; both Beckman Coulter, Inc., Brea, CA, USA) and CD105 PE (MHCD10504; Invitrogen; Thermo Fisher Scientific, Inc.) were. The RNA Extraction kit (antibody total RNA fast extraction kit) was from Generay Biotech Co., Ltd. (Shanghai, China), the reverse transcription (RT) PrimeScript ${ }^{\mathrm{TM}}$ RT Master mix was from Takara Biotechnology Co., Ltd. (lot no. RR036A; Dalian, China) and the quantitative polymerase chain reaction (qPCR) SuperRealPreMix color was from Tiangen Biotech Co., Ltd. (SYBR Green; lot no. FP215; Beijing, China). Polyvinylidene difluoride (PVDF) membranes were from Merck KGaA $(0.45 \mu \mathrm{m})$ and Bio-Rad Laboratories, Inc. (0.2 $\mu \mathrm{m}$; Hercules, CA, USA). Color pre-dyed molecular weight standard were provided by Fermentas (Thermo Fisher Scientific, Inc.), and the electrochemiluminescence (ECL) Plus luminescent kit, the SDS-PAGE loading buffer (5X), Western and IP cell lysis buffer, phenylmethylsulfonyl fluoride and the bicinchoninic acid (BCA) kit were obtained from Beyotime Institute of Biotechnology (Haimen, China). Primer sequences were as follows: IL-6, forward 5'-TAGTGAGGAACAAGCCAGAG-3' and reverse 3'-ATGCTACATTTGCCGAAGAG-5'; IL-1 $\beta$, forward 5'-TTACAGTGGCAATGAGGATG-3' and reverse 3'-TGTAGTGGTGGTCGGAGATT-5'; stem cell factor (SCF or Kit ligand), forward 5'-ATGGCTCCAGAAATGTCTAA-3' and reverse 3'-AATCCA ATCACAGTTCCCAC-5'; and GAPDH forward, 5'-AGAAGGCTGGGGCTCATTTG-3' and reverse, 3'-AGGGGCCATCCACAGTCTTC-5'. The following ELISA kits were used: VEGF [cat. no. EK1831; Hangzhou MultiSciences (Lianke) Biotech Co., Ltd.].

Separation, culturing and in vitro amplification of BMMSCs. Under aseptic conditions, BM from patients with MM (3-4 ml) was collected and placed into EDTA anticoagulant tubes or directly into chromosome culture bottles. To prepare single cell suspensions of the BM, BM cells were collected and mixed with 4-5 ml F solution (Tianjin Hao Yang Biological Products Technology Co., Ltd.), centrifuged for $20 \mathrm{~min}$ at $4^{\circ} \mathrm{C}$ and $500 \mathrm{xg}$. The supernatant was discarded, then the precipitate was washed twice with F solution and suspended with whole blood and tissue diluent containing 20\% FBS, which 
as also a part of the F soltuion kit. Separating medium ( $\geq 3 \mathrm{ml}$ ) was added to a 15-ml centrifuge tube, followed by the addition of an equal volume BM single cell suspension using a straw. The solution was centrifuged at $500 \mathrm{xg}$ and $4^{\circ} \mathrm{C}$ for $30 \mathrm{~min}$, and the annular milk and white lymphocytes, which formed the second layer from the top, were extracted and placed into a fresh $15-\mathrm{ml}$ centrifuge tube. A total of $10 \mathrm{ml}$ cleaning solution (cat. no. 2010X1118; Tianjin Hao Yang Biological Products Technology Co., Ltd.) was added and mixed with the cells. Following centrifugation at $250 \times \mathrm{g}$ and $4^{\circ} \mathrm{C}$ for $10 \mathrm{~min}$, the supernatant was discarded. Cells were resuspended in $0.5 \mathrm{ml}$ DMEM. Above steps were repeated 3 times. Following the final centrifugation step, cells were suspended with $0.5 \mathrm{ml}$ DMEM. Resuspended cells were counted and seeded at $10^{5}$ cells $/ \mathrm{cm}$ in a counting plate, containing $10 \% \mathrm{FBS}$ and low-glucose DMEM. Cells were incubated at $37^{\circ} \mathrm{C}$ in $5 \% \mathrm{CO}_{2}$ with saturated humidity. Following $24 \mathrm{~h}, \sim 25 \%$ of cells adhered onto the walls and $75-80 \%$ of cells adhered to the walls over the second and third days. Medium was replaced following 4 days. Following 1 week, $\sim 80 \%$ cell densities were achieved and cell passage was performed using trypsin.

Morphological observation and flow cytometric analysis of BMMSCs. Second generation BMMSCs were digested using trypsin, collected by centrifugation at $800 \mathrm{x} \mathrm{g}$ and $4^{\circ} \mathrm{C}$ for 5 min and the cellular morphology was observed under an optical microscope at a magnification of $x 40$ and x100. CD34 PE, CD45 PE and CD105 PE antibodies were added to the cells in the experimental group, and ISO IgG1 antibodies (cat. no. IM0670U; Beckman Coulter) were added to the control group at a density of at $1 \mu \mathrm{g}$ antibody $/ 10^{6}$ for $30 \mathrm{~min}$ at $4^{\circ} \mathrm{C}$. Cells were incubated for $30 \mathrm{~min}$ at $4^{\circ} \mathrm{C}$, detected by flow cytometry and analysed by BD Accuri ${ }^{\mathrm{TM}}$ C6 software (version 1.0.264.21; BD Biosciences, Franklin Lakes, NJ, USA).

Proliferation by CCK- 8 assay. Second generation BMMSCs were digested with $0.25 \%$ trypsin, centrifuged at $800 \mathrm{x} \mathrm{g}$ and $4^{\circ} \mathrm{C}$ for $5 \mathrm{~min}$, counted and seeded in 96-well plates at $5 \times 10^{3}$ cells/well. Cells were incubated standing still for $24 \mathrm{~h}$ at $37^{\circ} \mathrm{C}$. Equal volumes of $10 \%$ FBS in low-glucose DMEM (control group) or TPL at 6.25, 12.5, 25, 50 and $100 \mathrm{ng} / \mathrm{ml}$ in $10 \%$ FBS in low-glucose DMEM were added to the cells. Six replicates were performed in each group. Cells were cultured for 12, 24 and $48 \mathrm{~h}$, and harvested by centrifugation at $800 \mathrm{x} \mathrm{g}$ and $4^{\circ} \mathrm{C}$ for $5 \mathrm{~min}$. The supernatant was discarded and $10 \mu \mathrm{l} \mathrm{CCK-8} \mathrm{in} \mathrm{low-glucose} \mathrm{DMEM} \mathrm{(100} \mu \mathrm{l})$ was added to each well; cells in DMEM and $10 \%$ FBS were prepared as blanks. Reactions were incubated for $2 \mathrm{~h}$ at $37^{\circ} \mathrm{C}$ in the dark and optical density (OD) values was recorded at $450 \mathrm{~nm}$. Half maximal inhibitory concentration $\left(\mathrm{IC}_{50}\right)$ was calculated by SPSS software (version 17; SPSS, Inc., Chicago, IL, USA).

Apoptosis by flow cytometry. Second generation BMMSCs were digested with $0.25 \%$ trypsin, centrifuged at $800 \mathrm{xg}$ and $4^{\circ} \mathrm{C}$ for $5 \mathrm{~min}$, counted and seeded in 6 -well plates at $1 \times 10^{5}$ cells/well. Cells were further incubated for $24 \mathrm{~h}$ at $37^{\circ} \mathrm{C}$. Cells were incubated in $10 \%$ FBS in low-glucose DMEM with TPL at 25, 50 and $100 \mathrm{ng} / \mathrm{ml}$ or without TPL (the control group). Following $48 \mathrm{~h}$, cells were collected by centrifugation at $800 \mathrm{x}$ g and $4^{\circ} \mathrm{C}$ for $5 \mathrm{~min}$. Cells were washed twice with PBS and resuspended in binding buffer [cat. no. AP101-100-BB; $500 \mu \mathrm{l}$; Hangzhou MultiSciences (Lianke) Biotech Co., Ltd.]. A total of $5 \mu \mathrm{l}$ Annexin V-FITC and $10 \mu \mathrm{l}$ PI were added prior to incubation for $5 \mathrm{~min}$ at $4^{\circ} \mathrm{C}$ in the dark. Samples were detected using flow cytometry. All the experiments were repeated 3 times. Samples were analysed by BD Accuri ${ }^{\mathrm{TM}}$ C6 software.

IL-6, IL-1 $\beta$ and SCF mRNA expressions by RT-qPCR. TRIzol (cat. no. GK3016; Shanghai Generay Biotech Co., Ltd.) was used to extract total RNA from BMMSCs in the TPL group. RT of the total RNA was performed according to the manufacturer's instructions provided by the cDNA RT kit $\left(42^{\circ} \mathrm{C}\right)$. The total volume of the qPCR mixture was $30 \mu 1$, including RT product $(1 \mu \mathrm{l}), \mathrm{MgCl}_{2}(1.5 \mathrm{mM}), 1 \mathrm{X}$ PCR buffer, dNTPs $(0.5 \mathrm{mM})$, up- and downstream primers $(0.25 \mu \mathrm{M})$ and Taq DNA synthetase (1 U). IL-6, IL-1 $\beta$ and SCF reaction parameters were as follows: $94^{\circ} \mathrm{C}$ for $35 \mathrm{sec}$, followed by 40 cycles of $59^{\circ} \mathrm{C}$ for $45 \mathrm{sec}$ and $72^{\circ} \mathrm{C}$ for $30 \mathrm{sec}$, with a final extension at $72^{\circ} \mathrm{C}$ for $10 \mathrm{~min}$. The internal reference GAPDH. Products were directly used in electrophoresis or stored at $4^{\circ} \mathrm{C}$. All the experiments were repeated thrice. Relative gene expression data were analysed using Bio-Rad CFX Manager 3.1 (Bio-Rad Laboratories, Inc.) and the $2^{-\Delta \Delta \mathrm{Ct}}$ method (21).

P65 protein expression by western blotting. BMMSCs were treated with TPL and thalidomide (both 0, 25, 50 and $100 \mathrm{ng} / \mathrm{ml}$ ) for $48 \mathrm{~h}$ at $37^{\circ} \mathrm{C}$. Cells were harvested by centrifugation at $800 \mathrm{x} \mathrm{g}$ and $4^{\circ} \mathrm{C}$ for $5 \mathrm{~min}$ and the supernatant of the control group, TPL treatment group or thalidomide treatment group was discarded. Cells were washed twice with PBS and lysis buffer and protease inhibitor were added. The resulting solution was mixed by shaking for $1 \mathrm{~min}$ and then placed on ice for $10 \mathrm{~min}$. The mixing and incubation on ice were repeated thrice. Following centrifugation at $1,000 \times \mathrm{g}$ and $4^{\circ} \mathrm{C}$ for $5 \mathrm{~min}$, the protein concentration in the supernatant was detected using a BCA assay. Proteins $(40 \mu \mathrm{g})$ were separated by SDS-PAGE on a $12 \%$ separation gel and $5 \%$ concentrated gel, and then transferred to the $0.45 \mu \mathrm{m}$ PVDF membranes. Membranes were incubated with 5\% skimmed milk in TBST at room temperature for $2 \mathrm{~h}$. Anti-P65 (cat. no. ab7970; Abcam, Cambridge, UK) and anti-GAPDH (AP0063; Bioworld Technology, Inc., St. Louis Park, MN, USA) primary antibodies were added and incubated overnight at $4^{\circ} \mathrm{C}$. Subsequently, membranes were immersed in TBST and incubated with shaking 3 times for $15 \mathrm{~min}$ at $25^{\circ} \mathrm{C}$. Horseradish peroxidase-conjugated goat anti-mouse secondary antibodies (cat. no. bs12478; 1:5,000; Bioworld Technology, Inc.) were added and membranes were incubated with shaking for $2 \mathrm{~h}$ at room temperature. Membranes were immersed in TBST and incubated with shaking 3 times for $15 \mathrm{~min}$ at $25^{\circ} \mathrm{C}$. ECL detection reagent was added according to the manufacturer's instructions. The grey value of each band was analyzed using ImageJ (version 1.4; National Institutes of Health, Bethesda, MD, USA), following exporting the image in TIFF format. All the experiments were repeated thrice.

ELISA analysis of the vascular endothelial growth factor (VEGF) content in the culture supernatant. Cells from the 
A

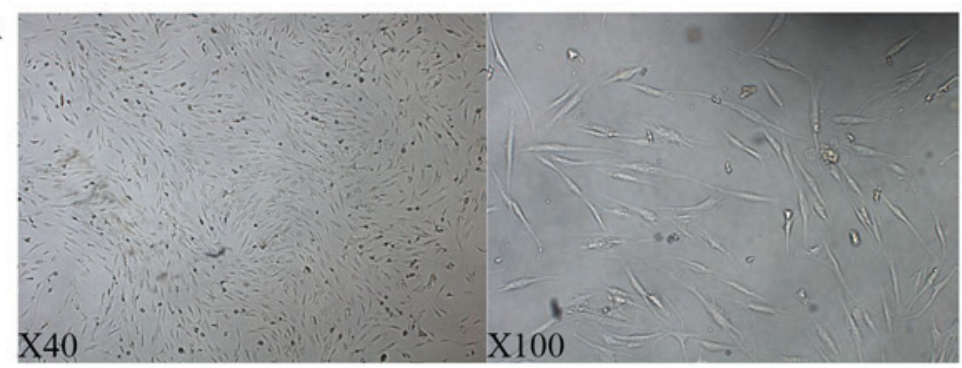

B

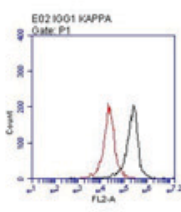

CD34

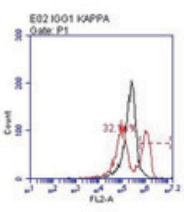

$\mathrm{CD} 45$

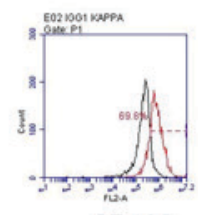

CD105
Figure 1. Identification of BMMSCs from patients with multiple myeloma. (A) Morphology of BMMSCs determined using light microscopy (magnification, $\mathrm{x} 40$ and x100). BMMSCs grew with increased adherence and exhibited a long spindle shape. (B) Immunophenotyping of BMMSCs using flow cytometry. Cells were CD34-negative, weak CD45-positive and CD105-positive. BMMSC, bone marrow-derived mesenchymal stem cell.
A

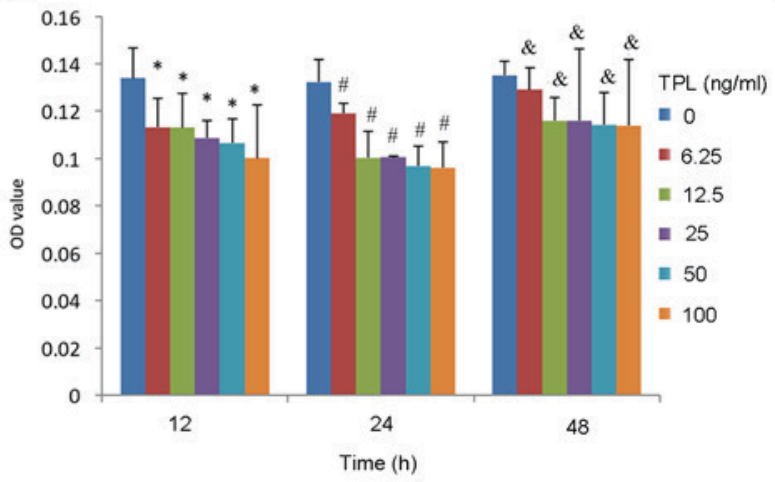

B

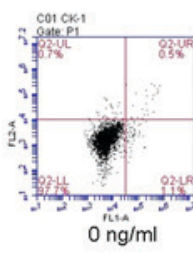

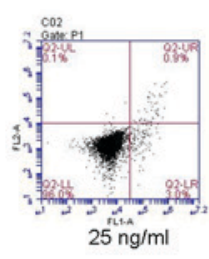

$25 \mathrm{ng} / \mathrm{ml}$

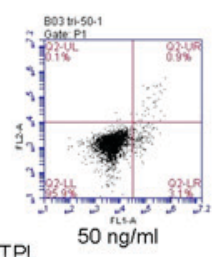

TPL
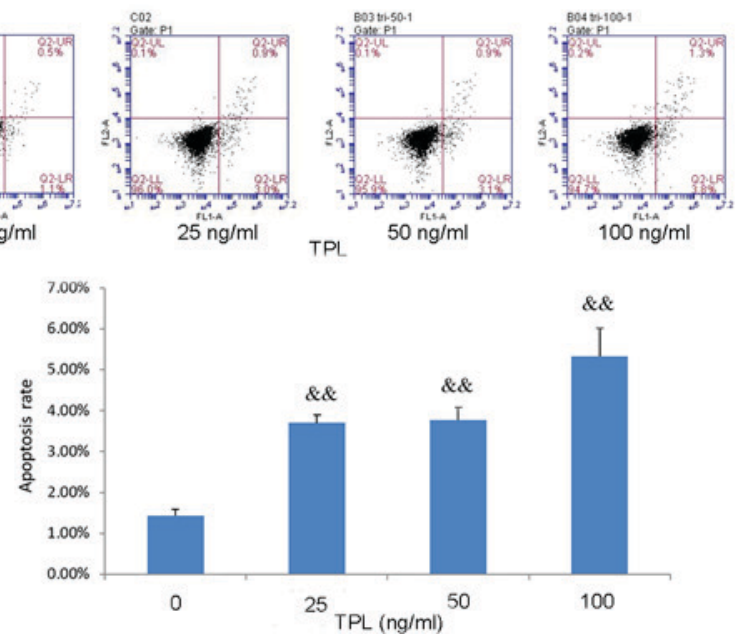

Figure 2. Effects of TPL on proliferation and apoptosis of BMMSCs from patients with multiple myeloma. (A) Effects of TPL (6.25, 12.5, 25, 50 and 100 ng/ml) on BMMSC proliferation determined by Cell Counting Kit- 8 assay. (B) Effects of TPL (0, 25, 50 and $100 \mathrm{ng} / \mathrm{ml})$ on apoptosis measured by flow cytometry. ${ }^{*} \mathrm{P}<0.05$ vs. untreated control at $12 \mathrm{~h} ;{ }^{*} \mathrm{P}<0.05$ untreated control at $24 \mathrm{~h} ;{ }^{\circledR} \mathrm{P}<0.05$, \&\& $\mathrm{P}<0.001$ vs. untreated control at $48 \mathrm{~h}$. TPL, triptolide; BMMSC, bone marrow-derived mesenchymal stem cell; OD, optical density.

control, and 25, 50 and $100 \mathrm{ng} / \mathrm{ml}$ TPL groups were analysed. According to the manufacturer's instructions, cell culture supernatant was removed from $-80^{\circ} \mathrm{C}$ and left to thaw at room temperature for $30 \mathrm{~min}$. The samples of the cells and standards were added into each well in a 96-well plate, except the blank well (with only contained DMEM). Plates were sealed and incubated at $37^{\circ} \mathrm{C}$ for $120 \mathrm{~min}$ to react to the antibodies prior to washing (6 times). Except for the blank, TBST working solution $(100 \mu \mathrm{l})$ was added, plates were sealed and incubated at $37^{\circ} \mathrm{C}$ for 45 min prior to washing (6 times). Then, except for the blank, enzyme binding working solution $(100 \mu \mathrm{l})$ was added, plates were sealed and incubated at $37^{\circ} \mathrm{C}$ for $30 \mathrm{~min}$ prior to washing (6 times). Substrate color developing agent $(100 \mu \mathrm{l})$ was added and plates were incubated at $37^{\circ} \mathrm{C}$ for $20 \mathrm{~min}$. Termination reaction solution $(100 \mu \mathrm{l})$ was added at $25^{\circ} \mathrm{C}$ for $30 \mathrm{~min}$ and $\mathrm{OD}$ values were determined at 490,570 or $630 \mathrm{~nm}$. All experiments were repeated thrice.

Statistical analysis. SPSS software was used to analyze the data. Data are expressed as mean \pm standard deviation. Univariate data was analyzed by one-way analysis of variance followed by the Least Significant Difference post hoc test. $\mathrm{P}<0.05$ was considered to indicate a statistically significant difference.

\section{Results}

Separation and identification of BMMSCs in culture. BMMSCs are adherent cells and in the current study they were separated from the BM following the addition of lymphocyte separating medium and screening with low-glucose DMEM. Cells exhibited a long-spindle shaped morphology and flow cytometry results indicated a CD34-negative, CD45 weak positive and CD105-positive expression (Fig. 1). All results complied with the characteristics of BMMSCs, namely a uniform long shuttle shape (22).

Effects of TPL on BMMSC proliferation and apoptosis. In order to investigate proliferation and apoptosis in TPL-treated BMMSCs, CCK-8 assays and flow cytometry were performed at varying TLP concentrations $(0,25,50$ and $100 \mathrm{ng} / \mathrm{ml})$ over time (12, 24 and $48 \mathrm{~h})$. At 12, 24 and $48 \mathrm{~h}$, the OD in TLP-treated BMMSCs (all concentrations) was significantly reduced compared with the untreated control sample $(\mathrm{F}=3.085$, $\mathrm{P}=0.023 ; \mathrm{F}=8.896, \mathrm{P}<0.001 ; \mathrm{F}=7.873, \mathrm{P}<0.001$, respectively; Fig. 2A). These results indicated that TPL inhibited the proliferation of BMMSCs compared with the untreated control. The $\mathrm{IC}_{50}$ of TPL at $48 \mathrm{~h}$ was $101.55 \pm 2.45 \mathrm{ng} / \mathrm{ml}$. Apoptosis in BMMSCs significantly increased in a concentration-dependent 
A

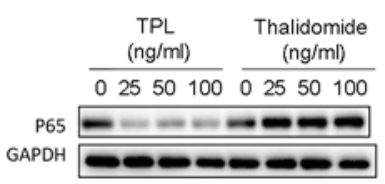

B

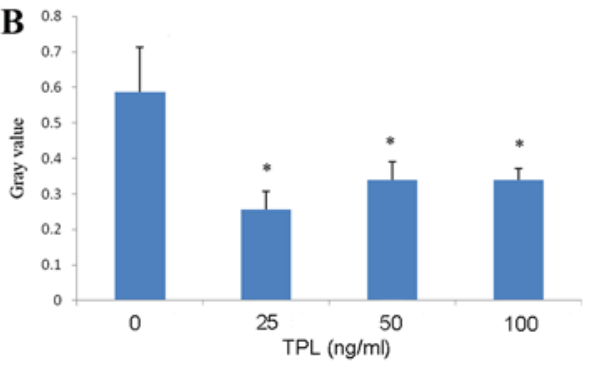

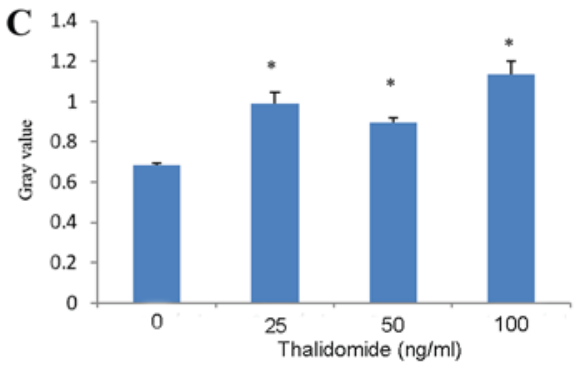

Figure 3. P65 protein expression in TPL- and thalidomide-treated BMMSCs. Western blotting (A) images and gray value analysis of P65 levels in (B) TPL$(0,25,50$ and $100 \mathrm{ng} / \mathrm{ml})$ and $(C)$ thalidomide-treated $(0,25,50$ and $100 \mathrm{ng} / \mathrm{ml})$ BMMSCs. ${ }^{*} \mathrm{P}<0.05$ vs. untreated control. TPL, triptolide; BMMSC, bone marrow-derived mesenchymal stem cell; P65, transcription factor p65.

Table I. Effects of TPL on IL-6, IL-1 $\beta$ and SCF mRNA expressions in bone marrow-derived mesenchymal stem cells.

\begin{tabular}{lcccc}
\hline & \multicolumn{4}{c}{ TPL $(\mathrm{ng} / \mathrm{ml})$} \\
\cline { 2 - 5 } Cytokine & 0 & 25 & 50 & 100 \\
\hline IL-6 & $1.00 \pm 0.02$ & $0.11 \pm 0.02^{\mathrm{a}}$ & $0.06 \pm 0.01^{\mathrm{a}}$ & $0.03 \pm 0.00^{\mathrm{a}}$ \\
IL-1 $\beta$ & $1.00 \pm 0.12$ & $0.69 \pm 0.09^{\mathrm{b}}$ & $0.13 \pm 0.05^{\mathrm{a}}$ & $0.05 \pm 0.03^{\mathrm{a}}$ \\
SCF & $1.00 \pm 0.01$ & $0.10 \pm 0.00^{\mathrm{a}}$ & $0.03 \pm 0.00^{\mathrm{a}}$ & $0.03 \pm 0.00^{\mathrm{a}}$
\end{tabular}

Data are presented as mean \pm standard deviation. ${ }^{\mathrm{a}} \mathrm{P}<0.001$ and ${ }^{\mathrm{b}} \mathrm{P}<0.05$ vs. untreated control. TPL, triptolide; IL, interleukin; $\mathrm{SCF}$, stem cell factor or Kit ligand.

manner at $48 \mathrm{~h}$, with rates of $1.43 \pm 0.15,3.70 \pm 0.20,3.77 \pm 0.32$ and $5.33 \pm 0.68 \%$ for $0,25,50$ and $100 \mathrm{ng} / \mathrm{ml} \mathrm{TPL}$, respectively ( $F=49.078, P<0.001$; Fig. 2B). These results suggested that TPL may induce apoptosis in BMMSCs.

$I L-6, I L-1 \beta$ and SCF mRNA expression by RT-qPCR. To investigate the effect of TLP on cytokines, RT-qPCR was performed to detect mRNA expression levels of IL-6, IL-1 $\beta$ and SCF. BMMSCs were treated with TPL $(0,25,50$ and $100 \mathrm{ng} / \mathrm{ml}$ ) for $48 \mathrm{~h}$. Analysis revealed that IL-6, IL-1 $\beta$ and SCF expression were significantly decreased with TPL treatment compared with the untreated controls in what appeared to be a dose-dependent manner $(\mathrm{F}=1433.475, \mathrm{P}<0.001 ; \mathrm{F}=90.057$, $\mathrm{P}<0.001 ; \mathrm{F}=11117.534, \mathrm{P}<0.001$; Table I). These findings suggested that TPL may decrease cytokine mRNA expression.

P65 protein expression analyzed by western blotting. To detect the effect of TPL and thalidomide on P65 protein levels, BMMSCs were treated with different TPL and thalidomide concentrations $(0,25,50$ and $100 \mathrm{ng} / \mathrm{ml})$ for $48 \mathrm{~h}$ and western blots were generated. Results indicated that with increasing TPL, P65 expression decreased ( $\mathrm{F}=7.489, \mathrm{P}=0.010$; Fig. 3). With increasing thalidomide, P65 expression markedly increased compared with the blank control $(\mathrm{F}=3.916, \mathrm{P}=0.054$; Fig. 3C). These results suggested that TPL downregulated P65 expression.

VEGF levels in the culture supernatant. To detect effects of TPL on VEGF levels, BMMSCs were treated with TPL
Table II. Effect of TPL on VEGF levels in the culture supernatant of bone marrow-derived mesenchymal stem cells.

TPL $(\mathrm{ng} / \mathrm{ml}) \quad$ Vascular endothelial growth factor $(\mathrm{pg} / \mathrm{ml})$

\begin{tabular}{rc}
\hline 0 & $2,642 \pm 34$ \\
25 & $1,479 \pm 733^{\mathrm{a}}$ \\
50 & $1,052 \pm 244^{\mathrm{a}}$ \\
100 & $561 \pm 59^{\mathrm{a}}$ \\
\hline
\end{tabular}

Data are presented as mean \pm standard deviation. ${ }^{\mathrm{a}} \mathrm{P}<0.05$ vs. untreated control. TPL, triptolide.

$(0,25,50$ and $100 \mathrm{ng} / \mathrm{ml})$ for $48 \mathrm{~h}$. VEGF levels significantly decreased with TPL treatment compared with the untreated controls in what appeared to be a dose-dependent manner $(\mathrm{F}=10.500, \mathrm{P}=0.023$; Table II). The lowest VEGF level $(561 \pm 59 \mathrm{pg} / \mathrm{ml})$ was measured at $100 \mathrm{ng} / \mathrm{ml} \mathrm{TPL}$.

\section{Discussion}

Recently, attention has focused on elucidating the mechanism of TPL in MM (23). A study evaluated several effects of TPL, ranging from antitumor mechanisms to inhibition of signaling pathway activation and regulation of histone expression (24). Few studies examined the effects of TPL on BMMSCs and the BM microenvironment $(25,26)$. Hence, the current study investigated the effects of TPL on BMMSCs obtained from patients with MM. BM from healthy individuals was not included in this investigation and it solely focused on the analysis of a tumor microenvironment. Effects of TPL at varying concentrations were compared with an untreated control group; however, no comparison to a healthy control was made, due to the absence of volunteers. BMMSCs constitute to the microenvironment of hematopoietic cell differentiation and development, and regulate hematopoiesis by expressing soluble cytokines and the ECM (16). The microenvironment serves an important role in differentiation and proliferation of normal bone tissue and plasma cells in the BM, including regulation of MM cell proliferation.

During the process of cell proliferation, cyclin B promotes the $\mathrm{G} 2$ to $\mathrm{M}$ transition and cyclin $\mathrm{A}$ and $\mathrm{D}$ promote the G1 to $\mathrm{S}$ transition (27). TPL downregulates cyclin A, $\mathrm{B}, \mathrm{C}$ and $\mathrm{D}$ expression, leading to an obstruction of the cell 
cycle and inhibition of cell proliferation (28). It has been demonstrated previously that TPL upregulates p27 and p21 expression and downregulates CDC25A and cyclin A, delaying progression from the $S$ phase (10). In the present study, TPL demonstrated inhibitory effects on BMMSC proliferation. An $\mathrm{IC}_{50}$ value of $101.55 \pm 2.45 \mathrm{ng} / \mathrm{ml}$ was determined. Furthermore, TPL stalled BMMSCs in the $\mathrm{S}$ phase and induced apoptosis. A dose-dependency was determined with $1.43 \pm 0.15$, $3.70 \pm 0.20,3.77 \pm 0.32$ and $5.33 \pm 0.68 \%$ apoptosis at $0,25,50$ and $100 \mathrm{ng} / \mathrm{ml} \mathrm{TPL}$, respectively. As the measured apoptotic rates were low, further experiments with higher TPL doses should be performed to validate these observations. The exact mechanism by which TPL affects the cell cycle of BMMSCs requires further verification.

$\mathrm{NF}-\kappa \mathrm{B}$, a polyphenic and multifunctional transcription factor, is present in the cytoplasm and is associated with the regulation of cell proliferation and apoptosis $(29,30)$. It has been reported that NF- $\kappa \mathrm{B}$ and inhibitor $(\mathrm{I}) \kappa \mathrm{B}$ proteins exhibited irregular expressions in various tumors and that NF- $\kappa \mathrm{B}$ is activated in various tumor cells $(31,32)$. Furthermore, NF- $\kappa B$ serves an important role in inhibiting tumor cell apoptosis, promoting tumor cell proliferation and tumor metastasis (31). There are various mechanisms by which NF- $\kappa B$ promotes tumorigenesis (33): i) Inducing anti-apoptotic genes, including B-cell lymphoma-XL, X-linked inhibitor of apoptosis protein and cellular inhibitor of apoptosis 1 and 2; ii) metastasis regulation, including cell adhesion and migration through intercellular adhesion molecule 1, vascular cell adhesion protein 1, endothelial-leukocyte adhesion molecule 1 , matrix metallopeptidase- 9 and urokinase-type plasminogen activator regulation; iii) angiogenesis regulation via VEGF, IL-1, IL-8 and tumor necrosis factor; iv) proliferation induction via oncogenes, including cyclin D1, c-myc; v) induction of telomerase for unlimited proliferation; vi) inflammation regulation via cyclooxygenase 2 and inducible nitric oxide synthase expression; vii) apoptosis induction via pro-apoptotic genes, including Fas and death receptor 4/5; viii) tumor suppressor gene activation and induction of apoptosis via protein 53 in human immunodeficiency virus; ix) anti-proliferation through c-Jun N-terminal kinase-inhibited proliferation, induced by cyclin-dependent kinase inhibitor $\mathrm{p} 21$ (WAF1/CIP1) expression; $\mathrm{x}$ ) transformation inhibition.

Thalidomide is a clinical medication, but TPL is not used as a clinical hematological drug, so thalidomide was used as a positive control in the current study and, as TPL and thalidomide work ultimately through protein expression, we choose the western blot. In the current study, P65 expression in BMMSCs treated with TPL was decreased compared with the untreated control and the thalidomide group. As a result, it is suggested TPL affected BMMSCs through NF- $\kappa \mathrm{B}$ as $\mathrm{P} 65$ is in the NF- $\mathrm{kB}$ signaling pathway. In response, inhibition of NF- $\mathrm{kB}$ expression may decrease the release of various above-mentioned inflammatory factors.

In the present study, TPL inhibited the expression levels of cytokines, including IL-6, IL-1 $\beta$, SCF and VEGF, which are associated with the constitution of the BM microenvironment (17). The biological behavior of MM primary tumor cells and the clinical outcomes partially depend on the genome and epigenetic abnormity of the MM cells (34). The BM microenvironment serves a key role in the pathogenesis and development of MM (35-39). MM cells establish complicated interactions with other cellular constituents within the BM microenvironment. Consequences of these interactions are outlined in the following: MM cells primarily interact with BMMSCs and osteoclasts, leading to cell signaling pathway activation, including phosphatidylinositol 3 kinase/protein kinase B, Janus kinase/signal transduction and activating transcription factor 3, RAS/RAF/mitogen-activated protein kinase/extracellular signal-regulated kinase and NF- $\mathrm{KB}$; and MM cells promote proliferation, survival, metastasis and drug resistance $(34,39,40)$. In addition, MM cells disturb the equilibrium of the BM environment, leading to anemia, immunosuppression and uncoupling (41). The bone remodeling process results in the development of lytic bone lesions, which are characteristic in the development of MM (41). Results of the present study demonstrated that following TPL treatment, IL-6, IL-1 $\beta$ and SCF mRNA and VEGF protein levels in BMMSCs were significantly decreased compared with the untreated control. The BM microenvironment was improved to regulate the proliferation of MM cells by decreasing IL-6, IL-1 $\beta$ and SCF mRNA expression (14). Due to a close association of IL- 6 and VEGF expression with NF- $\kappa B$, decreased levels of IL-6 and VEGF may be associated with the TPL-mediated inhibition of NF- $\kappa B$ signal transduction. These findings were in accordance with previous results (42).

In conclusion, the current study suggested that in addition to the direct induction of BMMSC apoptosis, TPL indirectly affected proliferation of MM cells by inhibiting IL-6, IL-1 $\beta$ and SCF expression, and VEGF secretion. TPL further possessed a potential anti-MM effect, which may inspire future treatments for MM.

\section{Acknowledgements}

Not applicable.

\section{Funding}

The current study was supported by the Zhejiang Provincial Medical and Health Science and Technology Plan (grant no. KYA028), the Zhejiang Traditional Chinese Medicine Science Research Fund (grant no. 2015ZA021), and Zhejiang Provincial Department of Science and Technology (Zhejiang Provincial Natural Science Foundation; grant no. QY19H080001).

\section{Availability of data and materials}

The datasets used and/or analyzed during the current study are available from the corresponding author on reasonable request.

\section{Authors' contributions}

HW, YW and LR performed the experiments and analyzed the data. HW was a major contribution in writing the manuscript. WZ, YJ and SG screened and examined patients, and obtained the ethical approval. DT, CS, ZC analyzed and interpreted the 
data. HJ designed experiments and guided the experimental process. All authors read and approved the final manuscript.

\section{Ethics approval and consent to participate}

The current study was approved by the Ethics Committee of Tongde Hospital of Zhejiang Province (Hangzhou, China) and patients provided written informed consent.

\section{Patient consent for publication}

Not applicable.

\section{Competing interests}

The authors declare that they have no competing interests.

\section{References}

1. Engelhardt M, Terpos E, Kleber M, Gay F, Wäsch R, Morgan G, Cavo M, van de Donk N, Beilhack A, Bruno B, et al: European Myeloma Network recommendations on the evaluation and treatment of newly diagnosed patients with multiple myeloma. Haematologica 99: 232-242, 2014.

2. Gu WZ and Brandwein SR: Inhibition of type II collagen-induced arthritis in rats by triptolide. Int $\mathbf{J}$ Immunopharmacol 20 : 389-400, 1998

3. Cibere J, Deng Z, Lin Y, Ou R, He Y, Wang Z, Thorne A, Lehman AJ, Tsang IK and Esdaile JM: A randomized double blind, placebo controlled trial of topical Tripterygium wilfordii in rheumatoid arthritis: Reanalysis using logistic regression analysis. J Rheumatol 30: 465-467, 2003.

4. Liu H, Liu ZH, Chen ZH, Yang JW and Li LS: Triptolide: A potent inhibitor of NF-kappa B in T-lymphocytes. Acta Pharmacol Sin 21: 782-786, 2000 .

5. Zhao G, Vaszar LT, Qiu D, Shi L and Kao PN: Anti-inflammatory effects of triptolide in human bronchial epithelial cells. Am J Physiol Lung Cell Mol Physiol 279: L958-L966, 2000.

6. Qiu D, Zhao G, Aoki Y, Shi L, Uyei A, Nazarian S, Ng JC and Kao PN: Immunosuppressant PG490 (triptolide) inhibits T-cell interleukin-2 expression at the level of purine-box/nuclear factor of activated T-cells and NF-kappaB transcriptional activation. J Biol Chem 274: 13443-13450, 1999.

7. Zhou HF, Niu DB, Xue B, Li FQ, Liu XY, He QH, Wang XH and Wang XM: Triptolide inhibits TNF-alpha, IL-1 beta and NO production in primary microglial cultures. Neuroreport 14: 1091-1095, 2003.

8. Hu KB, Liu ZH, Liu D and Li LS: Inhibition of vascular endothelial growth factor expression and production by triptolide. Planta Med 68: 368-369, 2002.

9. Kim JH and Park B: Triptolide blocks the STAT3 signaling pathway through induction of protein tyrosine phosphatase SHP-1 in multiple myeloma cells. Int J Mol Med 40: 1566-1572, 2017.

10. Johnson SM, Wang X and Evers BM: Triptolide inhibits proliferation and migration of colon cancer cells by inhibition of cell cycle regulators and cytokine receptors. J Surg Res 168: 197-205, 2011.

11. Ding J, Huang S, Wang Y, Tian Q, Zha R, Shi H, Wang Q, Ge C, Chen T, Zhao Y, et al: Genome-wide screening reveals that miR-195 targets the TNF-/NF- $\mathrm{BB}$ pathway by down-regulating I $\mathrm{B}$ kinase alpha and TAB3 in hepatocellular carcinoma. Hepatology 58: 654-666, 2013.

12. Korde N, Kristinsson SY and Landgren O: Monoclonal gammopathy of undetermined significance (MGUS) and smoldering multiple myeloma (SMM): Novel biological insights and development of early treatment strategies. Blood 117: 5573-5581, 2011.

13. Buenrostro D, Mulcrone PL, Owens P and Sterling JA: The bone microenvironment: A fertile soil for tumor growth. Curr Osteoporos Rep 14: 151-158, 2016.

14. Zipori D: The hemopoietic stem cell niche versus the microenvironment of the multiple myeloma-tumor initiating cell. Cancer Microenviron 3: 15-28, 2010.
15. Ghobrial IM: Myeloma as a model for the process of metastasis: Implications for therapy. Blood 120: 20-30, 2012.

16. Wallace SR, Oken MM, Lunetta KL, Panoskaltsis-Mortari A and Masellis AM: Abnormalities of bone marrow mesenchymal cells in multiple myeloma patients. Cancer 91: 1219-1230, 2001.

17. Abe M: Development of the therapies targeting the interaction of myeloma cells with its bone marrow microenvironment. Rinsho Ketsueki 54: 522-532, 2013 (In Japanese).

18. Mizuno H, Kikuta J and Ishii M: Bone and stem cells. Intravital imaging of bone marrow microenvironment. Clin Calcium 24 541-546, 2014 (In Japanese).

19. Verger E, Salamero M and Conill C: Can Karnofsky performance status be transformed to the Eastern Cooperative Oncology Group score scoring scale and vice versa? Eur J Cancer 28A 1328-1330, 1992.

20. Rajkumar SV, Dimopoulos MA, Palumbo A, Blade J, Merlini G, Mateos MV, Kumar S, Hillengass J, Kastritis E, Richardson $\mathrm{P}$, et al: International Myeloma Working Group updated criteria for the diagnosis of multiple myeloma. Lancet Oncol 15: e538-e548, 2014.

21. Livak KJ and Schmittgen TD: Analysis of relative gene expression data using real-time quantitative PCR and the 2(-Delta Delta C(T)) method. Methods 25: 402-408, 2001.

22. Hu Y, Ma L, Ma G, Jiang X and Zhao C: Comparative study of human fetal and adult bone marrow derived mesenchymal stem cells. Zhonghua Xue Ye Xue Za Zhi 23: 645-648, 2002 (In Chinese).

23. Yinjun L, Jie J and Yungui W: Triptolide inhibits transcription factor NF-kappaB and induces apoptosis of multiple myeloma cells. Leuk Res 29: 99-105, 2005.

24. Wen L, Chen Y, Zeng LL, Zhao F, Yi S, Yang LJ, Zhang BP, Zhao J, Zhao ZC and Zhang C: Triptolide induces cell apoptosis by targeting $\mathrm{H} 3 \mathrm{~K} 4 \mathrm{me} 3$ and down-stream effector proteins in KM3 multiple myeloma cells. Curr Pharm Biotechnol 17: 147-160, 2015.

25. Carter BZ, Mak DH, Shi Y, Fidler JM, Chen R, Ling X, Plunkett W and Andreeff M: MRx102, a triptolide derivative, has potent antileukemic activity in vitro and in a murine model of AML. Leukemia 26: 443-450, 2012.

26. Sun L, Li H, Zhang L and Zhou H: Anticancer properties of triptolide: Inhibition of tumor-associated macrophages differentiation and cytokine production. FASEB J 30: 1193-1199, 2016.

27. Knoblich JA and Lehner CF: Synergistic action of Drosophila cyclins A and B during the G2-M transition. EMBO J 12: 65-74, 1993.

28. Hung FM, Chen YL, Huang AC, Hsiao YP, Yang JS, Chung MT, Chueh FS, Lu HF and Chung JG: Triptolide induces $S$ phase arrest via the inhibition of cyclin $\mathrm{E}$ and $\mathrm{CDC} 25 \mathrm{~A}$ and triggers apoptosis via caspase- and mitochondrial-dependent signaling pathways in A375.S2 human melanoma cells. Oncol Rep 29: 1053-1060, 2013

29. Chen Y, Vallee S, WU J, Vu D, Sondek J and Ghosh G: Inhibition of NF-kappaB activity by IkappaBbeta in association with kappaB-Ras. Mol Cell Biol 24: 3048-3056, 2004.

30. Biswas DK, Shi Q, Baily S, Strickland I, Ghosh S, Pardee AB and Iglehart JD: Activation of NF-kappa B in human breast cancer specimens and its role in cell proliferation and apoptosis. Proc Natl Acad Sci USA 101: 10137-10142, 2004.

31. Grosjean-Raillard J, Tailler M, Adès L, Perfettini JL, Fabre C, Braun T, De Botton S, Fenaux P and Kroemer G: ATM mediates constitutive NF-kappaB activation in high-risk myelodysplastic syndrome and acute myeloid leukemia. Oncogene 28: 1099-1109, 2009.

32. Yun JM, Afaq F, Khan N and Mukhtar H: Delphinidin, an anthocyanidin in pigmented fruits and vegetables, induces apoptosis and cell cycle arrest in human colon cancer HCT116 cells. Mol Carcinog 48: 260-270, 2009.

33. Dutta J, Fan Y, Gupta N, Fan G and Gélinas C: Current insights into the regulation of programmed cell death by NF-kappaB. Oncogene 25: 6800-6816, 2006.

34. Munshi NC and Avet-Loiseau H: Genomics in multiple myeloma. Clin Cancer Res 17: 1234-1242, 2011.

35. Hideshima T, Mitsiades C, Tonon G, Richardson PG and Anderson KC: Understanding multiple myeloma pathogenesis in the bone marrow to identify new therapeutic targets. Nat Rev Cancer 7: 585-598, 2007.

36. Mitsiades CS, Mitsiades NS, Munshi NC, Richardson PG and Anderson KC: The role of the bone microenvironment in the pathophysiology and therapeutic management of multiple myeloma: Interplay of growth factors, their receptors and stromal interactions. Eur J Cancer 42: 1564-1573, 2006. 
37. Podar K, Chauhan D and Anderson KC: Bone marrow microenvironment and the identification of new targets for myeloma therapy. Leukemia 23: 10-24, 2009.

38. Basak GW, Srivastava AS, Malhotra R and Carrier E: Multiple myeloma bone marrow niche. Curr Pharm Biotechnol 10: 345-346, 2009.

39. Yasui H, Hideshima T, Richardson PG and Anderson KC: Novel therapeutic strategies targeting growth factor signalling cascades in multiple myeloma. Br J Haematol 132: 385-397, 2006.

40. Podar K, Richardson PG, Hideshima T, Chauhan D and Anderson KC: The malignant clone and the bone-marrow environment. Best Pract Res Clin Haematol 20: 597-612, 2007.
41. Garcia-Gomez A, Sanchez-Guijo F, Del Cañizo MC, San Miguel JF and Garayoa M: Multiple myeloma mesenchymal stromal cells: Contribution to myeloma bone disease and therapeutics. World J Stem Cells 6: 322-343, 2014.

42. Ma JX, Sun YL, Wang YQ, Wu HY, Jin J and Yu XF: Triptolide induces apoptosis and inhibits the growth and angiogenesis of human pancreatic cancer cells by downregulating COX-2 and VEGF. Oncol Res 20: 359-368, 2013.

(i) $($ ) This work is licensed under a Creative Commons Attribution-NonCommercial-NoDerivatives 4.0 International (CC BY-NC-ND 4.0) License. 